\title{
Effects of calcium-vitamin D and metformin on the menstrual cycle and ovulation in polycystic ovary syndrome patients in a tertiary care teaching hospital
}

\author{
Gowthami Mummalaneni ${ }^{1}$, Krishna Kumari Myneni ${ }^{2 *}$
}

\begin{abstract}
${ }^{1}$ Department of Obstetrics and Gynecology, Maharajah's Institute of Medical Sciences, Nellimarla, Vizianagaram, Andhra Pradesh, India

${ }^{2}$ Department of Obstetrics and Gynecology, Muvva Gopala Hospital, Vizianagaram, Andhra Pradesh, India
\end{abstract}

Received: 19 December 2020

Accepted: 26 February 2021

\section{*Correspondence:}

Dr. Krishna Kumari Myneni,

E-mail: krishnakumarimyneni9@gmail.com

Copyright: (c) the author(s), publisher and licensee Medip Academy. This is an open-access article distributed under the terms of the Creative Commons Attribution Non-Commercial License, which permits unrestricted non-commercial use, distribution, and reproduction in any medium, provided the original work is properly cited.

\begin{abstract}
Background: Polycystic ovary syndrome (PCOS) is a heterogeneous hormonal disorder of reproductive aged women characterized by chronic anovulation, irregular menstrual cycles and hyperandrogenism. The present study aimed to investigate the effects of metformin and calcium-vitamin D on follicular maturation and regularity of menstrual cycles in patients with PCOS.

Methods: A prospective, open-label, multiple arms, randomized clinical trial. Group 1 participants received 1,000 mg of calcium and $400 \mathrm{IU}$ of vitamin D per day, orally, group 2 participants received 1,500 $\mathrm{mg}$ of metformin per day, orally and group 3 participants received combination of above drugs. The patients were treated for 3 months and followed up for a further 3 months. Menses regularity, number of dominant follicles $(\geq 14 \mathrm{~mm})$ and pregnancy rates were compared among the three groups.

Results: A total of sixty infertile women with PCOS were recruited. Calcium-vitamin D plus metformin treated patients showed highest percentage improvement (50\%) menstrual regularity as compared to other two groups $(\mathrm{p}<0.001)$ also showed significant follicular response $(\mathrm{p}<0.014)$. Calcium-vitamin D plus metformin treated group showed better follicular response in the second and third month of follow-up and $30 \%$ of women showed high quality dominant large ( $\geq 14 \mathrm{~mm}$ ) follicles at the end of follow-up period.

Conclusions: Calcium-vitamin D plus metformin combination is more effective in terms of follicle maturation and restoring menstrual disturbances as compared to individual drug treatment.
\end{abstract}

Keywords: Calcium-Vitamin D, Ovulation, Menstrual cycle, Metformin, PCOS

\section{INTRODUCTION}

Polycystic ovary syndrome (PCOS) is one of the common causes of infertility in women and it affects $6-10 \%$ of reproductive age. ${ }^{1}$ The adverse clinical features of PCOS include irregularities in menstrual cycles, androgen excess symptoms, fat deposition and obesity. ${ }^{2,3}$ Simply by looking at the number of polycystic ovaries or clinical manifestations of hyperandrogenism, studies which focus on pregnancy as a primary outcome with anovulation as the identifying symptom has good clinical impact. ${ }^{4}$ Regular menstrual cycles and hyperandrogenism women are at higher risk of insulin resistance as compared with irregular menstrual cycles and chronic hyperandrogenism and/or polycystic ovary disease. ${ }^{5,6}$

Women with metabolic features such as amenorrhea/chronic oligomenorrhea in comparision with regular menstrual cycles have to be stratified in PCOS, those studies are very essential to conduct and execute in clinical setting. There is no higher abnormal androgen in circulating blood with PCOS and large proportion of patients has been reported. ${ }^{7,8}$ PCOS management is uncertain and main focus of drug therapy to be 
amelioration of the clinical features. Pregnancy can be achieved if effectively restrain the ovulatory cycles is the main aim of the treatment in PCOS. ${ }^{9}$

Several published randomized clinical have been reported that metformin $500 \mathrm{mg}$ TDS per day or $850 \mathrm{mg}$ BDS per day with meals shows effective as menstrual regularity, increases the frequency of spontaneous ovulation, and ovulatory response to clomiphene in women with PCOS..$^{10,11}$ However, efficacy and safety of long term use of insulin-sensitizing agents like metformin is not recommended due to lack of evidence. ${ }^{12}$

Calcium role in oocyte activation and maturation have been established in recent animal experiments which further helps in restarts and progression of follicular development. ${ }^{13}$ A study conducted by Steinhardt et al in 1974 reported that calcium have beneficial and universal role in egg activation and maturation. ${ }^{14}$ From there, mammalian oocytes take the calcium and involved in the regulation of both mitotic and meiotic cell divisions which gain the interest in recent times. ${ }^{15}$ The importance of calcium as discussed above in terms of oocyte activation and maturation, hence, disturbance in the homeostasis of calcium may contribute the pathogenesis of PCOS. ${ }^{16}$ It is a fact that several previous studies also suggested that vitamin D also plays a crucial role in reproductive functions. Ovaries and testis expressed and up-regulated vitamin D receptor suggesting that vitamin$\mathrm{D}$ is active in these organs. ${ }^{17}$ With this background, the present study aimed to investigate the effects of metformin and calcium-vitamin D on follicular maturation and regularity of menstrual cycles were investigated in PCOS patients.

\section{METHODS}

A prospective, open-label, multiple arms, randomized clinical trial was conducted at Department of Obstetrics and Gynecology, Maharaja Institute of Medical Sciences, Vijayanagaram, Andhra Pradesh during the period of August 2019 to July 2020. The present study was approved by scientific committee as well as Institutional Ethics Committee and informed consent was obtained from all of the study participants before commencement of the study. Study was conducted according to the Declaration of Helsinki.

The present study enrolled 60 infertile women aged between 21-35 years old who met the Rotterdam criteria for PCOS.

\section{Inclusion criteria}

Patients were included in the study according to the Rotterdam criteria with the presence of at least two or three characteristics mentioned here: (1) oligomenorrhea/ amenorrhea (2) biochemical or clinical findings of hyperandrogenism, and (3) transvaginal sonography findings of polycystic ovaries.

\section{Exclusion criteria}

The following patients with systemic diseases were excluded from the study suchas hyperparathyroidism, Cushing's syndrome, hyperprolactinemia, history ofabdominal/pelvic surgery, androgen secreting tumors, abnormal hysterosalpingography, coexisting male infertility.

After recruiting the study subjects, we performed extensive and elaborative personal interview to ascertain their baseline demographic details. A questionnaire has been prepared then standardized for their use to get the dietary habits. Subsequent we underwent through physical and clinical examinations which includes biochemical hormonal analyses and radiological sonography. Endocrine diagnostic tests were also included to rule out the further etiology including thyroid-stimulating hormone, serum levels of prolactin, follicle-stimulating hormone, luteinizing hormone, serum and urinary levels of calcium. On day three of the menstrual cycle, transvaginal sonography was done to access the baseline details. Every three days from day eight of menstruation again same transvaginal sonography was performed to determine the follicular growth until at least one dominant follicle $(14 \mathrm{~mm})$ appearance.

Study participants were allotted to three groups of 20 participants each using computer generated randomization table. Group 1 participants received 1,000 $\mathrm{mg}$ of calcium and $400 \mathrm{IU}$ of vitamin $\mathrm{D}$ as a single formulation in two dividing doses $(500 \mathrm{mg}$ calcium and 200 IU vitamin-D- morning and night) per day, orally. Group 2 participants received 1,500 $\mathrm{mg}$ of metformin per day, orally (500 $\mathrm{mg}$ tablet in three dividing doses). Group 3 participants received $1,000 \mathrm{mg}$ of calcium $+400 \mathrm{IU}$ of vitamin $\mathrm{D}$ plus metformin $1,500 \mathrm{mg} /$ day, orally. All tablets were advised to be taken orally with plenty of water. Drug therapy was started on the first day of menstrual cycle and continued for 3 consecutive months. Once drug treatment completed, study participants were followed up next 3 months.

Menses regularity i.e. 21-35 days interval, follicular growth from $3^{\text {rd }}$ month to $6^{\text {th }}$ month was compared among the study groups. Based on the size of the follicle, follicle growth was categorized into three groups such as no response $(5-9 \mathrm{~mm})$, borderline $(10-14 \mathrm{~mm})$ and large $(\geq 14 \mathrm{~mm}$ ) at mid-cycle by using transvaginal sonography. Data analysis was performed using SPSS version 11 (SPSS Inc., Chicago, IL, USA). All descriptive statistics were showed as percentages, mean and standard deviation. Difference in baseline demographics among study groups was analyzed by analysis of variance (ANOVA) test. Regularity pattern of menstrual cycles and follicular growth at different intervals was analyzed by using chi-square test. $\mathrm{P}<0.05$ set as a statistically significant. 


\section{RESULTS}

A total of sixty infertile women with PCOS were recruited and conducted the study. Baseline patient demographic details were showed in Table 1. Their mean age was $25.91 \pm 4.36$ years, and body mass index (BMI) was $24.98 \pm 3.64$. Among the three study groups, ANOVA did not showed significance difference which was showed in Table $1(\mathrm{p}=0.595$ and $\mathrm{p}=0.623)$. More than $65 \%$ of study participants were consuming below the recommended daily allowance of dairy products.
Carbohydrates and proteins are taking as per recommendations. Mean duration of infertility was $4.6 \pm 2.5$ years. Both mean plasma $(9.50 \pm 1.36 \mathrm{mg} / \mathrm{dl})$ and urinary $(184.34 \pm 40.23 \mathrm{mg} / \mathrm{dl})$ calcium levels were within the normal range (8.6-10.2 $\mathrm{mg} / \mathrm{dl}$ for plasma and $50-300$ $\mathrm{mg} / \mathrm{dl}$ urinary samples, respectively). Around $80-90 \%$ and $10-15 \%$ of women had a history of oligomenorrhea and amenorrhea in the past 6 months prior to recruiting the study (Table 1) and there is no significant difference between among all study groups.

Table 1: Patients' characteristics.

\begin{tabular}{|c|c|c|c|c|c|}
\hline Variable & $\begin{array}{l}\text { Group } 1 \\
\text { (Ca-D; n=20) }\end{array}$ & $\begin{array}{l}\text { Group } 2 \\
\text { (met; n=20) }\end{array}$ & $\begin{array}{l}\text { Group } 3 \text { (Ca-D } \\
\text { + met; } n=20)\end{array}$ & Total & P value \\
\hline Age (years) & $26.14 \pm 4.5$ & $25.12 \pm 4.1$ & $26.48 \pm 4.5$ & $25.91 \pm 4.36$ & 0.595 \\
\hline BMI & $24.34 \pm 3.32$ & $25.24 \pm 3.85$ & $25.36 \pm 3.74$ & $24.98 \pm 3.64$ & 0.623 \\
\hline Duration of infertility (years) & $4.5 \pm 2.5$ & $4.9 \pm 2.8$ & $4.4 \pm 2.2$ & $4.6 \pm 2.5$ & 0.802 \\
\hline Plasma calcium (mg/dl) & $9.24 \pm 1.3$ & $9.90 \pm 1.5$ & $9.36 \pm 1.3$ & $9.5 \pm 1.36$ & 0.276 \\
\hline Urinary calcium (mg/dl) & $184.26 \pm 40.21$ & $188.12 \pm 42.14$ & $180.78 \pm 38.36$ & $184.38 \pm 40.23$ & 0.847 \\
\hline FSH (mIU/ml) & $5.26 \pm 1.28$ & $5.12 \pm 1.08$ & $5.01 \pm 1.00$ & $5.13 \pm 1.12$ & 0.782 \\
\hline LH (mIU/ml) & $9.95 \pm 3.24$ & $10.14 \pm 3.78$ & $9.81 \pm 3.12$ & $9.96 \pm 3.38$ & 0.953 \\
\hline Prolactin (mg/ml) & $240.10 \pm 48.18$ & $226.64 \pm 42.26$ & $248.13 \pm 49.08$ & $259.41 \pm 46.50$ & 0.345 \\
\hline \multicolumn{6}{|l|}{ Type of infertility, $n$ (\%) } \\
\hline Primary & $16(80)$ & $15(75)$ & $16(80)$ & $47(78.3)$ & \multirow{2}{*}{0.906} \\
\hline Secondary & $4(20)$ & $5(25)$ & $4(20)$ & $13(21.7)$ & \\
\hline \multicolumn{6}{|l|}{ Oligomenorrhea, n (\%) } \\
\hline Yes & $18(90)$ & $19(95)$ & $18(90)$ & 55 (91.6) & \multirow{2}{*}{0.803} \\
\hline No & $2(10)$ & $1(5)$ & $2(10)$ & $5(8.4)$ & \\
\hline \multicolumn{6}{|c|}{ History of oligomenorrhea (in last 6 months), $n$ (\%) } \\
\hline Yes & $17(85)$ & $18(90)$ & $16(80)$ & $51(85.0)$ & \multirow{2}{*}{0.675} \\
\hline No & $3(15)$ & $2(10)$ & $4(20)$ & $9(15.0)$ & \\
\hline \multicolumn{6}{|l|}{ Amenorrhea, n (\%) } \\
\hline Yes & $3(15)$ & $5(25)$ & $2(10)$ & $10(16.6)$ & \multirow{2}{*}{0.431} \\
\hline No & $17(85)$ & $15(75)$ & $18(90)$ & $50(83.4)$ & \\
\hline \multicolumn{6}{|c|}{ History of amenorrhea (in last 6 months), $\mathrm{n}(\%)$} \\
\hline Yes & $4(20)$ & $5(25)$ & $4(20)$ & $13(21.6)$ & \multirow{2}{*}{0.906} \\
\hline No & $16(80)$ & $15(75)$ & $16(80)$ & $47(78.4)$ & \\
\hline
\end{tabular}

Data are presented as mean \pm standard deviation and number with percentages; ANOVA and Chi-square tests were used to calculate the $\mathrm{p}$ values. $\mathrm{BMI}=$ Body mass index $; \mathrm{Ca}-\mathrm{D}=$ calcium-vitamin $\mathrm{D} ;$ Met $=$ Metformin $; \mathrm{FSH}=$ follicle-stimulating hormone $\mathrm{LH}=$ luteinizing hormone

Table 2: Regularity pattern of menstrual cycles after treatment in the treatment groups.

\begin{tabular}{|c|c|c|c|}
\hline Menses pattern & Group 1 (Ca-D; n=20) & Group 2 (met; $n=20$ ) & Group 3 (Ca-D + met; n=20) \\
\hline \multicolumn{4}{|l|}{ Before treatment } \\
\hline Regular:irregular & $2(10): 18(90)$ & $1(5): 19(95)$ & $1(5): 19(95)$ \\
\hline \multicolumn{4}{|l|}{ After treatment } \\
\hline Regular:irregular & $5(25): 15(75)$ & $6(30): 14(70)$ & $12(55): 8(45)$ \\
\hline$\%$ improvement & 15 & 25 & 50 \\
\hline$P$ value & $<0.001$ & & \\
\hline
\end{tabular}

Chi-square tests were used to calculate the P-values. Ca-D = calcium-vitamin D; Met = Metformin.

After third month of the drug treatment, women showed menstrual regularity which was estimated as percentage of improvement $15 \%, 25 \%$ and $50 \%$ of women in Group
1, 2 and 3 respectively (Table 2). Group 3 treated patients with calcium-vitamin $\mathrm{D}+$ metformin showed highest percentage improvement $(50 \%)$ in terms of menstrual 
regularity as compared to other two groups. Chi-square test showed statistical significance $(\mathrm{p}<0.001)$ among three study groups.

Table 3: Follicular growth after treatment in the treatment groups.

\begin{tabular}{|c|c|c|c|}
\hline $\begin{array}{l}\text { Follicular } \\
\text { response }\end{array}$ & $\begin{array}{l}\text { Group } 1 \\
\text { (Ca-D; } \\
\text { n=20) }\end{array}$ & $\begin{array}{l}\text { Group } 2 \\
\text { (met; } \\
\mathbf{n = 2 0})\end{array}$ & $\begin{array}{l}\text { Group } 3 \\
\text { (Ca-D + met; } \\
\text { n=20) }\end{array}$ \\
\hline \multicolumn{4}{|l|}{ At third month } \\
\hline No & $18(90 \%)$ & $19(95 \%)$ & $15(75 \%)$ \\
\hline $\begin{array}{l}\text { Borderline (10-14 } \\
\mathrm{mm})\end{array}$ & $2(10 \%)$ & $0(0)$ & $2(10 \%)$ \\
\hline Yes $(\geq 14 \mathrm{~mm})$ & $0(0)$ & $1(5 \%)$ & $3(15 \%)$ \\
\hline \multicolumn{4}{|l|}{ At fourth month } \\
\hline No & $18(90 \%)$ & $18(90 \%)$ & $15(75 \%)$ \\
\hline $\begin{array}{l}\text { Borderline (10-14 } \\
\mathrm{mm})\end{array}$ & $2(10 \%)$ & $1(5 \%)$ & $1(5 \%)$ \\
\hline Yes $(\geq 14 \mathrm{~mm})$ & $0(0)$ & $1(5 \%)$ & $4(20 \%)$ \\
\hline \multicolumn{4}{|l|}{ At fifth month } \\
\hline No & $17(85 \%)$ & $16(80 \%)$ & $12(60 \%)$ \\
\hline $\begin{array}{l}\text { Borderline (10-14 } \\
\mathrm{mm})\end{array}$ & $1(5 \%)$ & $3(15 \%)$ & $2(10 \%)$ \\
\hline Yes $(\geq 14 \mathrm{~mm})$ & $2(10 \%)$ & $1(5 \%)$ & $6(30 \%)$ \\
\hline \multicolumn{4}{|l|}{ At sixth month } \\
\hline No & $16(80 \%)$ & $13(65 \%)$ & $10(50 \%)$ \\
\hline $\begin{array}{l}\text { Borderline (10-14 } \\
\mathrm{mm})\end{array}$ & $1(5 \%)$ & $3(15 \%)$ & $3(15 \%)$ \\
\hline Yes $(\geq 14 \mathrm{~mm})$ & $3(15 \%)$ & $4(20 \%)$ & $7(35 \%)$ \\
\hline
\end{tabular}

$\mathrm{Ca}-\mathrm{D}=$ calcium-vitamin $\mathrm{D} ;$ Met $=$ Metformin .

Follicular response and their growth after drug treatment were showed in Table 3. Treatment with calcium-vitamin $\mathrm{D}+$ metformin showed significant follicular response $(\mathrm{p}<0.014)$ compared to group 1 (calcium-vitamin D treated) and group 2 (metformin treated). If group 2 compared to group 1, follicular response is relatively higher in group 2 but not statistically significant $(p<0.13)$. The likelihood of treatment response was about thrice as high in Group 3 as in Group 1 (odds ratio, 3.21). At fifth and sixth month follow-up period, group 3 showed relative higher frequency of follicular response then in other two groups. A total of $30 \%$ of women in group 3 showed high quality large $(\geq 14 \mathrm{~mm})$ follicles at the end of sixth month of follow-up (Table 3). In any of the study groups, pregnancy did not observed at the end of sixth month follow-up period.

\section{DISCUSSION}

Among several female endocrine disorders, PCOS is identified as one of the most common disorder. Disease has series of characteristics and symptoms which includes irregular menses, hyperandrogenism, long lasting anovulation, infertility and hirsutism. ${ }^{18}$ Nearly half $(50 \%)$ of the study participants showed improvement after treating with calcium-vitamin $\mathrm{D}+$ metformin as compared to calcium-vitamin alone (15\%) and metformin alone $(25 \%)$. Oocyte maturation can be influenced by calcium which was published by several studies conducted on invertebrates and amphibians. In addition, calcium role in human oocyte maturation also confirmed. ${ }^{19-21}$ Kitai et al conducted a study and reported that verapamil tetracaine, a calcium channel blocker involved oocyte arrest in meiosis. ${ }^{22}$ Low plasma vitamin $\mathrm{D}$ levels either due to deficiency or malabsorption or inadequate sun may leads to initiation and development of PCOS in women. Hence, dietary restore of this vitamin may revert the abnormal and irregular menstrual cycles in PCOS patients. ${ }^{23}$ As discussed above, dietary supplementation of calcium in combination with vitamin $\mathrm{D}$ effectively corrects the menstrual irregularities and their associated symptoms in PCOS patients. ${ }^{24}$

The present study conducted in such a way that patients received 3-month drug treatment in continuation with 3month follow-up period in all three groups with PCOS in addition with oligomenorrhea. The present study also assessed the calcium and vitamin D effects on irregularities of menstrual cycles and infertility. Calciumvitamin D plus metformin group has showed significant improvements in menstrual irregularities. To confirm this, randomized clinical trials with higher sample size are warranted which can be given clear relationship between menstrual regularity and calcium-vitamin Dmetformin treatment. Thys-Jacobs et al, conducted a study and observed that calcium-vitamin D $(1,500 \mathrm{mg}) 2$ months treatment showed regular menstrual cycles in seven subjects out of 13 women with irregular menstrual cycles with PCOS. ${ }^{16}$

In the present study, among calcium-vitamin D plus metformin group and calcium, metformin alone group, combination therapy found statistical significant in terms of follicular growth. It clearly indicates that calciumvitamin $\mathrm{D}$ plus metformin treated group showed better response in the second and third month of follow-up than other two groups. Pre-clinical studies strongly reported the effect of calcium on follicular development. ${ }^{25,26}$ Velazquez et al conducted a study on metformin and reported that insulin and androgen levels were reduced after 6 months of metformin therapy and regulating menstrual cycles in which fertility has been restored in patients with PCOS. ${ }^{27}$ In the present study, more than $65 \%$ of study subjects not taking the recommended daily allowance of dietary products in all study groups i.e. less than $1500 \mathrm{mg} /$ day of calcium rich foods which includes milk, butter, cheese, lassi and yoghurt. ${ }^{28}$ However, all study groups showed normal desired range of plasma calcium concentrations. Another study conducted by Homa et al reported that extracellular calcium levels are within the normal range but intracellular calcium levels are found to be low and showed abnormal oocyte function. ${ }^{15}$

\section{CONCLUSION}

Calcium-vitamin D is responsible for bone health and fertility, so administration of these agents suggest 
possible routes for treatment of these patients. Calciumvitamin D plus metformin combination is more effective in terms of maturation of follicles, restoring menstrual disorders than either drug alone. Calcium-vitamin D plus metformin treated group showed better follicular response in the second and third month of follow-up than other two groups. In detail study of mechanisms of drugs allows to take more cost-effective steps in PCOS patients.

Funding: No funding sources

Conflict of interest: None declared

Ethical approval: The study was approved by the Institutional Ethics Committee

\section{REFERENCES}

1. Ganie MA, Vasudevan V, Wani IA, Baba MS, Arif T, Rashid A. Epidemiology, pathogenesis, genetics and management of polycystic ovary syndrome in India. Indian J Med Res. 2019;150(4):333.

2. Witchel SF, Oberfield SE, Peña AS. Polycystic ovary syndrome: pathophysiology, presentation, and treatment with emphasis on adolescent girls. J Endocr Soc. 2019;3(8):1545-73.

3. El Hayek S, Bitar L, Hamdar LH, Mirza FG, Daoud G. Poly cystic ovarian syndrome: an updated overview. Front Physiol. 2016;7.

4. Group TREP consensus workshop. Revised 2003 consensus on diagnostic criteria and long-term health risks related to polycystic ovary syndrome (PCOS). Hum Reprod. 2004;19(1):41-7.

5. Robinson S, Kiddy D, Gelding SV, Willis D, Niththyananthan R, Bush A, et al. The relationship of insulin insensitivity to menstrual pattern in women with hyperandrogenism and polycystic ovaries. Clin Endocrinol. 1993;39(3):351-5.

6. Baptiste CG, Battista MC, Trottier A, Baillargeon JP. Insulin and hyperandrogenism in women with polycystic ovary syndrome. J Steroid Biochem Mol Biol. 2010;122(1-3):42-52.

7. Rodriguez Paris V, Bertoldo MJ. The Mechanism of Androgen Actions in PCOS Etiology. Med Sci. 2019;7(9).

8. Asunción M, Calvo RM, San Millán JL, Sancho J, Avila S, Escobar-Morreale HF. A prospective study of the prevalence of the polycystic ovary syndrome in unselected Caucasian women from Spain. J Clin Endocrinol Metab. 2000;85(7):2434-8.

9. Kamalanathan S, Sahoo JP, Sathyapalan T. Pregnancy in polycystic ovary syndrome. Indian $\mathrm{J}$ Endocrinol Metab. 2013;17(1):37-43.

10. Diamanti-Kandarakis E, Kouli C, Tsianateli T, Bergiele A. Therapeutic effects of metformin on insulin resistance and hyperandrogenism in polycystic ovary syndrome. Eur J Endocrinol. 1998;138(3):269-74.

11. Nestler JE, Jakubowicz DJ, Evans WS, Pasquali R. Effects of metformin on spontaneous and clomiphene-induced ovulation in the polycystic ovary syndrome. N Engl J Med. 1998;338(26):187680.

12. Ledger WL. Non-reproductive consequences of polycystic ovary syndrome. Curr Obstet Gynaecol. 2003;13(6):350-4.

13. De Felici M, Dolci S, Siracusa G. An increase of intracellular free $\mathrm{Ca}^{2+}$ is essential for spontaneous meiotic resumption by mouse oocytes. J Exp Zool. 1991;260(3):401-5.

14. Steinhardt RA, Epel D, Carroll EJ, Yanagimachi R. Is calcium ionophore a universal activator for unfertilised eggs? Nature. 1974;252(5478):41-3.

15. Homa ST, Carroll J, Swann K. The role of calcium in mammalian oocyte maturation and egg activation. Hum Reprod Oxf Engl. 1993;8(8):1274-81.

16. Thys-Jacobs S, Donovan D, Papadopoulos A, Sarrel P, Bilezikian JP. Vitamin D and calcium dysregulation in the polycystic ovarian syndrome. Steroids. 1999;64(6):430-5.

17. Stumpf WE. Vitamin D sites and mechanisms of action: a histochemical perspective. Reflections on the utility of autoradiography and cytopharmacology for drug targeting. Histochem Cell Biol. 1995;104(6):417-27.

18. Bednarska S, Siejka A. The pathogenesis and treatment of polycystic ovary syndrome: What's new. Adv Clin Exp Med. 2017;26(2):359-67.

19. Kaufman ML, Homa ST. Defining a role for calcium in the resumption and progression of meiosis in the pig oocyte. J Exp Zool. 1993;265(1):69-76.

20. Ullah G, Jung $\mathrm{P}$, Machaca K. Modeling $\mathrm{Ca}^{2+}$ signaling differentiation during oocyte maturation. Cell Cal. 2007;42(6):556-64.

21. Lee JH, Yoon SY, Bae IH. Studies on $\mathrm{Ca}^{2+}$-channel distribution in maturation arrested mouse oocyte. Mol Reprod Dev. 2004;69(2):174-85.

22. Kitai H, Santulli R, Wright KH, Wallach EE. Examination of the role of calcium in ovulation in the in vitro perfused rabbit ovary with use of ethyleneglycol-bis (beta-aminoethyl ether)-n,n'tetraacetic acid and verapamil. Am J Obstet Gynecol. 1985;152(6 Pt 1):705-8.

23. Lin $\mathrm{MW}, \mathrm{Wu} \mathrm{MH}$. The role of vitamin $\mathrm{D}$ in polycystic ovary syndrome. Indian $\mathrm{J}$ Med Res. 2015;142(3):238-40.

24. Miao CY, Fang XJ, Chen Y, Zhang Q. Effect of vitamin $\mathrm{D}$ supplementation on polycystic ovary syndrome: a meta-analysis. Exp Ther Med. 2020;19(4):2641-9.

25. Touyz RM, Jiang L, Sairam RM. Follicle-stimulating hormone mediated calcium signaling by the alternatively spliced growth factor type I receptor. Biol Reprod. 2000;62(4):1067-74.

26. Chen W, Xia WG, Ruan D, Wang S, Abouelezz KFM, Wang SL, et al. Dietary calcium deficiency suppresses follicle selection in laying ducks through mechanism involving cyclic adenosine monophosphate-mediated signaling pathway. Animal. 2020;14(10):2100-8. 
27. Velázquez ME, Acosta A, Mendoza SG. Menstrual cyclicity after metformin therapy in polycystic ovary syndrome. Obstet Gynecol. 1997;90(3):392-5.

28. Cormick G, Belizán JM. Calcium Intake and Health. Nutrients. 2019;11(7).
Cite this article as: Mummalaneni G, Myneni KK. Effects of calcium-vitamin D and metformin on the menstrual cycle and ovulation in polycystic ovary syndrome patients in a tertiary care teaching hospital. Int J Reprod Contracept Obstet Gynecol 2021;10:1442-7. 